\title{
Comparative Analysis of Early Studies on Turkish Whistle Language and a Case Study on Test Conditions
}

\author{
Selma Ozaydin \\ Department of Electronics \& Communication Engineering, Cankaya University, Ankara, Turkey \\ Email: selmaozaydin@yahoo.com
}

How to cite this paper: Ozaydin, S. (2018). Comparative Analysis of Early Studies on Turkish Whistle Language and a Case Study on Test Conditions. Open Journal of Modern Linguistics, 8, 126-136. https://doi.org/10.4236/ojml.2018.84013

Received: April 27, 2018

Accepted: August 4, 2018

Published: August 7, 2018

Copyright (c) 2018 by authors and Scientific Research Publishing Inc. This work is licensed under the Creative Commons Attribution International License (CC BY 4.0).

http://creativecommons.org/licenses/by/4.0/

\section{(c) (i) Open Access}

\begin{abstract}
This paper examines the early studies on Turkish Whistle Language and it argues that they have some controversial results. The study considers these issues need to be discussed and searched again in terms of linguistic and phonetic form. Unfortunately, there are few research studies on Turkish whistle language and most of them were performed nearly fifty years ago despite the fact that this language still has been used in Kuskoy region. Therefore, the findings of these early research studies could give valuable information to start to a new research study on the subject. The first scientific study on Turkish Whistle language was performed by a French scientist R.G. Busnel with his multidisciplinary research team in 1967. Some of this research's results were published in the book. A Turkish scientist O. Baskan also participated in Busnel's research group and published a paper on TWsL in 1968. However, some assertions such as people having a tendency to understand the Turkish whistle language with three vowels and three consonants have not been in the research results of R.G. Busnel. In addition, a Turkish scientist D. Aksan in Turkey had performed another research at Kuskoy region with his own team. Their test methods were different from the previous ones. This paper analyzes these research results on a comparative basis and presents the common and conflicted issues to discuss the uncertain points. The comparative evaluation of these past research studies aims to highlight the controversial position of the results on Turkish Whistle Language. In this scope, this paper opens a discussion about the selection of test conditions for an acoustic and linguistic analysis of the Turkish whistle language.
\end{abstract}

\section{Keywords}

Turkish Whistle Language, Whistled Speech, Kuskoy, Phonetic, Linguistic 


\section{Introduction}

A comprehensive linguistic study about whistle language (WsL) was published in 1948 (Cowan, 1948). It was about a WsL used in Massatecs and it was stated that people can communicate in long distances by whistling and with the similar speed and intelligibility like in spoken language. In fact, in whistled speech people can still articulate words and thereby transform spoken utterances into whistled melodies, syllable by syllable. Whistling production can be described as a shock effect of the compressed air stream inside the cavity of the mouth and/or of the hands and it doesn't require the vibration of vocal cords. For whistling, the lips are tight and the sound is produced by the turbulence of the air forced either into the smallest hole of the vocal tract or against an edge (depending of the technique). The reduced mouth cavity acts as a resonator to tune the sounds. When the jaws are fixed by a finger, the size of the hole is stable. The air stream expelled makes vibrations at the edge of the mouth. The faster the air stream is expelled, the higher is the noise inside the cavities. If the hole (mouth) and the cavity (intra-oral volume) are well matched, the resonance is tuned, and the whistle is projected more loudly. In whistling, both the control of air flow and the physiological constraints are important to guarantee the efficient emission of the articulation of words. Therefore, tension of the muscles of the vocal tract increases. These tensions reinforce the concentrations of energy in the signal. In a whistled signal spoken signals are changed in terms of frequency (pitch), intensity (magnitude of loudness) and time (durations). Because a WsL is based on spoken speech, the whistles may have some prosodic properties of the whistler such as gender, age or even mood. Whistled speech is unintelligible for an untrained person which gives a secrecy during communication (Baskan, 1968; Meyer, 2007b).

A WsL requires a training stage. Once a person trained, he spends less vocal effort in a whistled speech according to spoken speech because vocal cord does not tire. A whistler can raise the pitch of his whistle by increasing the air pressure and with this way he can increase the resistance against reverberation as well as the background noise and also he can increase the distance that a whistle can reach. WsL has some advantages according to the normal speech due to its pure tone. The frequency range of WsL is usually between $1000-4000 \mathrm{~Hz}$ and this is the most sensitive frequency band of human ear. The pitches of the main band of frequencies of whistles are concentrated in this narrow bandwidth. With this property, a whistle can be heard even in most noisy environment. Furthermore, a WsL is open to articulate new signs. But this is based on the human capability of a WsL.

Kuskoy is a village located near the Black Sea in Turkey and the whistle language in Kuskoy was learnt by the world via some international newspapers. One of them, The New York Times published an article with a title "Turkish town talks in Whistles" (New York Times, 1964). Another similar article published in London. Then, a French Scientist Busnel had performed the first scien- 
tific research on this language in Kuskoy region with a multidisciplinary research team in 1967 and this study was financed by the Wenner Gren Foundation. Professor Busnel described Kuskoy as a large region covering 35 villages which were scattered over an area of nearly $5000 \mathrm{~km}^{2}$ consisting steep hills and deep narrow valleys. The settlement in the region was also described as scattered (Busnel, 1976). During Busnel's research, they both recorded voices for perception tests and captured the X-ray images of the vocal tracts of speakers while whistlers were speaking and whistling some sentences and analyzed them with the help of specialists in psychology, acoustics, signal treatment, biology, ethology and linguistics. In their research study, Turkish whistle language was found to function very similarly to another whistle language Silbo Gomero (in Spain), despite the much more complex vocalic system of the Turkish language. A Turkish lingustic Professor, O. Baskan also participated in the scientific research group mentioned above and published a paper on TWsL in 1968 (Baskan, 1968). On the other hand, some claims in his paper such as Turkish whistle language was whistled with the phonetic reduction of Turkish has not been found in the test results on Turkish whistle language in (Busnel, 1976). Another Turkish Linguistic Professor, D. Aksan had not participated in this research studies but had done a research at Kuskoy region with his own team and they performed a recognition test on TWsL (Aksan, 1968). This paper argues the research results of these early studies on a comparative basis and presents the common and conflicted results to discuss the uncertain points in these past studies. The comparative evaluation of these past research studies, which had been performed nearly at the same time period but seems resulted with different findings, aims to highlight the controversial position of TWsL research studies and to discuss the proper statistical test conditions of the TWsL for a possible new research study.

\section{Analysis of Research Results on Turkish Whistle Language in Early Studies}

If we start to examine the studies on TWsL in a chronologic sequence, we can start with the paper of O. Başkan (Baskan, 1968). Turkish whistled speech production is described in this paper as follows; A whistle is produced by sending of the air from a small groove formed in the tip of a tongue and spoken words are sent by putting on this modulating whistle wave like as sending of a signal on a high frequency carrier wave. As a result, whistled speech signal is produced by a compressed air stream at the entrance of oral cavity. At this time, soft plate closes the nose hole, lips are stretched and then tip of the lips touch the sides of tongue to prevent the leakage, lower lips curled back by closing the lower teethes to close the sides of the groove. Owing to these, voice is sent with maximum energy from a groove by preventing air leakage mostly. Thus, the melody of the whistled sentences is satisfied with the lower and higher form of voice like in normal speech and word emphasis is satisfied with the necessary energy. With all these properties the TWsL can be described as an incomplete form of Turkish 
language. Therefore, completion method is used by the listener to reproduce the said words (Baskan, 1968).

Baskan's research results can be briefed as follows; the Kuskoy residents learnt TWsL by making practice to whistle words in their mother language and it takes nearly 3 years for a person to whistle all kinds of words by whistling. The TWsL in Kuskoy cannot be said as a closed form of a whistled speech based on the definite signs. Because, it can be reproduced to define new words in Turkish. All articulation activities are continued during whistling and therefore this whistle language can be said as a form of mixture of speaking and whistling. The TWsL can also be called as an incomplete form of speech like a whispering or speaking from nose. The distance of a whistle that can reach is not affected from the gender and a listener mostly can understand the gender of a person when he listened a whistling. Besides, listening tests showed that whistling person could be understood from his whistling style like his speaking style (Baskan, 1968).

Even though Busnel (Busnel, 1976) and Baskan (Baskan, 1968) were participated within the same research group during the research on TWsL in 1967, some phonetic inferences in (Baskan, 1968) have not been in (Busnel, 1976). It is interestingly stated in (Baskan, 1968) that according to the listening and understanding tests performed in Kuskoy, people has a tendency to understand the TWsL with three vowels ( $i, œ, o$ ) and three consonants ( $f, t f, k)$ even if Turkish Language has thirty-two phonemes including eight vowels (Figure 1) and twenty-four consonants (Table 1). According to Baskan, thirty-two Turkish phoneme family was piled up within these six distinct sounds in TWsL, even though a whistling person is described as tried to make all the necessary movements to speak the same sentence. The reason of this explained in (Baskan, 1968) as follows; both vowels (i, œ, o) and consonants (f, $t$, $k$ ) have front, middle and back articulation points respectively in accordance with the physiology of whistling in TWsL. The main articulation points are front and back points. Middle point can be regarded as an average of these two. /o/ and $/ \mathrm{t} f /$ voices carry the heaviest load of the TWsL for vowels and consonants respectively. Vocal cords do not vibrate while whistling and therefore voiced consonants (such as $/ c /, / d /$ ) cannot be produced. Furthermore, because lips are not closed, bilabial consonants (such as $/ \mathrm{p} /, \mathrm{b} / \mathrm{l} / \mathrm{m} /$ ) can be produced as /f/. Because of the tongue, which satisfies the modulation by sticking to palate while whistling, many phonemes approximated to / $\mathrm{t} f$. Similarly, because semi-constricted condition of lips ends in parallel with the small rise of tongue, the condition of voice system similar to vowel/o/. For all these reasons, heavy load of TWsL is carried by /o/ and / $\mathrm{t} /$ sounds as can be seen from the Table 1. On the other hand, because a whistling person performs all necessary movements for articulating, he assumes he can extract all the necessary sounds even if he can only extract them as 3 vowels and 3 consonants. Moreover, the listening person tries to decode all acoustic properties of whistling and can understand them as 3 vowels and 3 consonants (Baskan, 1968). 


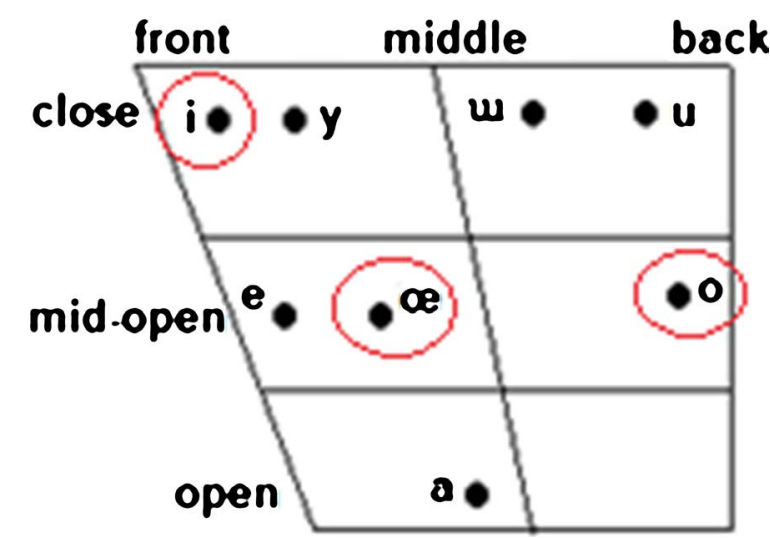

Figure 1. Turkish vowel trapezoid according to International Phonetic Alphabet (IPA) (1999: p. 155) and corresponding vowels in TWsL (in circles) by considering the theory in (Baskan, 1968).

Table 1. Twenty-four Turkish Consonants in (International Phonetic Alphabet (IPA), 1999: p. 154) and the corresponding three consonants in TWsL (in squares) by considering the theory in (Baskan, 1968).

\begin{tabular}{|c|c|c|c|c|c|c|c|c|}
\hline & Bilabial & $\begin{array}{l}\text { Labio- } \\
\text { dental }\end{array}$ & Glottal & Dental & Alveolar & \begin{tabular}{l|} 
Post- \\
alveolar
\end{tabular} & Palatal & Velar \\
\hline $\begin{array}{l}\text { Plosive } \\
\text { and Affricate }\end{array}$ & p b & & & $\begin{array}{ll}t & d\end{array}$ & & t $\int d_{3}$ & C $f$ & k $\quad \mathrm{g}$ \\
\hline Nasal & $m$ & & & $n$ & & & & \\
\hline Fricative & & f $\quad v$ & $\mathrm{~h}$ & $z$ & & $\int 3$ & & $\gamma$ \\
\hline Tap & & & & & $r$ & & & \\
\hline Approximant & & & & & & & $\mathrm{j}$ & \\
\hline $\begin{array}{l}\text { Lateral } \\
\text { Approximant }\end{array}$ & & & & 1 & & 1 & & \\
\hline
\end{tabular}

Turkish vowel trapezoid with eight vowels can be seen in Figure 1. By considering the theory in (Baskan, 1968), the place of 3 vowels in TWsL are indicated in red circles in Figure 1. As can be seen from Figure 1, these three vowels are localized in the front, middle and back of the articulation points. Besides, The classification of twenty-four Turkish consonants according to IPA (1999) presented in Table 1 and the corresponding 3 consonants in TWsL is indicated in squares by considering the theory in (Baskan, 1968). Some examples of normal speech and whistled form of them with those six sounds can be seen in the Table 2. It is recommended by the author of this paper that word recognition performance of TWsL and the claim of a tendency to understand the TWsL with only six sounds (i, œ, o, f, t $\int$, $k$ ) worths to search again with a comprehensive test setup in order to get new outputs on linguistic and acoustic properties.

In order to prove the six whistle phonemes mentioned above really in fact exists in TWsL, a word recognition test was said to have been performed by Baskan (Baskan, 1968). There is no much details about the number of participants and 
Table 2. According to (Baskan, 1968), some examples of understanding of Turkish spoken words in whistled from with six sound group as illustrated below.

\begin{tabular}{|c|c|c|c|}
\hline Spoken word & Whistled form & Spoken word & Whistled form \\
\hline İmece & ifœt $\int œ$ & gel- & kœt $\int-$ \\
\hline Jandarmalar & $\mathrm{t} \int \operatorname{ot} \int \mathrm{t} \int \operatorname{ot} \int$ fot $\int \mathrm{ot} \int$ & sœyle & $t \int œ t \int t \int œ$ \\
\hline Muhtar & foft $\int$ ot $\int$ & tas1- & $\mathrm{t}$ fot $\mathrm{o}_{\mathrm{-}}$ \\
\hline Sabah & $\mathrm{t}$ fofof & -ecegim & 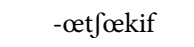 \\
\hline Buraya & fotfotfo & -irmisin & -itffitfits \\
\hline ormancIlar & ot $\int$ fot $\int \mathrm{t}$ [ot $\int \mathrm{ot} \int$ & & \\
\hline
\end{tabular}

used test words in (Baskan, 1968). During the test, some sentences were constructed according to above-mentioned six sounds. Then, it was claimed to the whistling person that those sentences were belong to some foreign language. They were asked to whistle those sentences. Afterwards, these whistled sentences were recorded and those recordings had been listened to some other people living there. These recordings were interestingly converted to the normal speech correctly by those people. It was also seen during the test that normal spoken words were encoded into TWsL, syllabus by syllabus. Incomplete syllabuses were completed by the listener with the completion method (Baskan, 1968).

On the contrary, to Baskan's undefined word recognition test conditions in (Baskan, 1968), Busnel (Busnel, 1976) describes his recognition test conditions in Kuskoy as follows; the recordings with whistled words and spoken form of them were prepared and 92 different non-semantic spoken/whistled words including isolated words and sentences were obtained. Then, testers (5 men, 2 women) were asked to listen them from a loudspeaker and answer some questions about sex, age, identity of person and spoken word of the recordings. While the correction result is about $\% 96$ for normal speech it was about $\% 59$ for whistled speech. There is no much details about the non-semantic words used during the test. It is also stated in (Busnel, 1976) that test conditions were too limited to evaluate the results as a statistical test. Even if the experimental setup is too limited to evaluate it as a statistical test, test results show that while word recognition error is about $\% 4$ for a spoken word, it increases about to $\% 30$ in whistled speech. The author explains this condition as artificially isolated words might reduce the quality of word recognition especially for the words starting with a consonant. In addition, low understandability could also be due to the effect of used loudspeaker instead of a live source. Furthermore, similar whistled words from different performers were compared and it was seen that even if they had unequal duration and pitch range, they had similar contours and the similarity rate could be extracted by a machine more correctly instead of using testers (Busnel, 1976). Busnel also describes the whistled language as an acoustically simplified version of speech due to the preservation of most of the lexis, syntax and phonologic information in a whistled form. He states that several parameters specifying the acoustic aspect of an utterance are replaced by a frequency 
modulation of a simple wave. But, it is not seen in his test results in (Busnel, 1976) that people has a tendency to understand the TWsL with three vowels and three consonants.

As an another research example on TWsL, Aksan's team prepared a test list with words and sentences including all phonemes of Turkish (Aksan, 1968). They prepared this list by selecting the words including the phonemes of Turkish at the initial, internal or final sound of a word in order to evaluate their reflections in the TWsL. They also added some foreign words to this list. And then, they performed a test by recording the voices of the participants while whistling the words in that list from near or far distances. The results showed that whistlers could convert nearly all the words in the list into whistled form even they heard a foreign word. Some of the test results can be briefed as follows; Aksan stated that the phonemes within the bilabial, alveolar or dental group (such as, $\mathrm{p}$, $\mathrm{b}, \mathrm{t} \int, \int, \mathrm{r}, \mathrm{l}, \mathrm{n}$ ) were difficult to extract while whistling especially when they had been as a final sound in a word. On the other hand, for example a fricative phoneme $\mathrm{v}$ had been in an initial or internal sound, it could be understood very well. If the phonemes like $\mathrm{t} \int$ or $\int$ was combined with vowels $a$ or $w$, the understandability rate increased. Aksan stated that the role of mouth aparture decreased and the role of vocal tract increased due to the special condition of tongue while whistling. He also stated that the roles of thick and thin vowels were high in understanding of a TWsL (Aksan, 1968).

J. Meyer performed on TWsL for a statistical analysis of vowels and consonants (Meyer, 2007a). In order to obtain a large corpus of vowels and consonants, he used the data recorded by R.G. Busnel in Kuskoy in 1967 (Busnel, 1976) and the data recorded by J. Meyer in 2003. In this study, the frequency distribution of whistled vowels and the consonants in TWsL was presented. According to the statistical analysis of 8 Turkish vowels in TWsL, there was an overlap among some vowel frequencies and therefore frequencies of these whistled vowels were combined in 4 main bands of frequencies such that [(i), $(\mathrm{Y}, \mathrm{w})$, (e, œ, u), (a, o)] according to vocalic harmony rules in Turkish. They are accepted as statistically distinct in these groups (this result seems compatible with the theory that Turkish whistled vowels can be piled up in (i, œ, o) in (Baskan, 1968)). Then, it is concluded that there were some phonetic reductions in TWsL while a phonologic structure was preserved. It is also stated that whistled Turkish could be a good model to further analyze the perception of both the vowels and the modulations underlying in the complex formant distribution of the spoken voice (Meyer, 2007a).

\section{Determining of Test Conditions for a Statistical Analysis of Turkish Whistle Language}

\subsection{The First Test Studies on TWsL}

Baskan (Baskan, 1968) states that TWSL is based on Turkish language. He claims that people still continued to pronunciation movements while whistling 
and thus the result was again a language mixed with whistles. He also claims that people can whistle any Turkish or foreign word that can be asked. He describes the experiment conditions as based on the received words instead of sent words. Understandability tests were made by using far-distance people and words and syllables within oral or recorded test data were used in these understandability tests. Some of the test data were selected from meaningless syllabuses such as ("da", "se", "bi", "up", “edu", etc). There is no much information about the test conditions and the number of testers as well as the correction test results in this study.

Aksan's team performed a test by using a list with words and sentences including all phonemes of Turkish (Aksan, 1968). They selected the words including the phonemes of Turkish at the initial, internal or final sound of a word. They also added some foreign words and performed a test from near or far distances. They selected the phonemes within the bilabial, alveolar or dental group were difficult to extract while whistling. According to test results, Aksan stated that the role of mouth aperture decreased and the role of vocal tract increased due to the special condition of tongue while whistling. He also stated that the roles of thick and thin vowels were high in understanding of a TWsL (Aksan, 1968).

The other scientist, Busnel (Busnel, 1976) performed a recognition test in Kuskoy with 92 different non-semantic spoken/whistled words including isolated words and sentences. 7 testers ( 5 men, 2 women) were used in the tests. Why the number of participants are limited to seven is not clear in the paper. There is no much details about the words used during the tests. It is also stated in (Busnel, 1976) that test conditions were too limited to evaluate the results as a statistical test. The recognition tests were performed in terms of word, sex, age and identity recognition. The test results showed that whistled speech were highly intelligible even for non-standardized sentences.

\subsection{A Case Study on Test Conditions of a Whistle Language}

Due to the lack of performed acoustic and linguistic tests on TWsL and limited information about test conditions during these tests, a question raises that what could be the best test conditions and corpus test data to evaluate the test results of TWsL as a statistical test. Besides, a methodology is required to evaluate the phonetic and phonologic aspect of TWsL in terms of vowels and consonants. For instance, articulation of each phonemes during spoken speech and their whistled form can be analyzed in a spectogram for both vowel and consonants by comparison of their curve outputs one by one. The changes in formant locations, duration and intensity in both cases can be evaluated. Phonological analysis should also be considered by analysis of articulation points during production of phonemes while whistling or speaking. How prosodic information is preserved in a whistled form of speech is another question that should be investigated during the tests. 
A scientific research of a whistle language requires the design of a specific methodology adapted to the special acoustic form of it. Many questions should be raised and answered before an acoustic or phonetic/phonological analysis of the TWsL. Some of them are listed as follows; What could be the adequate number of whistlers during the recognition tests? Could a gender distribution of whistlers be an important factor for the collected data? What could be the dialogues to be used as the test material? Could it be enough to select spontaneous dialogues or should it be based on a phonetic balance of the carefully selected words and sentences? Which phonetic or phonological tools can be used during topological comparison of the results? Could it be sufficient an acoustic analysis of the results by blind approach to the shapes of the frequencies in whistled form (without knowing the linguistic content). TWsL can be the best example of a whistle language to give an answer all these questions with a new research study due to its preserved form up to now.

For a possible research study on TWsL, some of the test conditions are recommended as follows; First of all, a language based investigation requires a multidisciplinary study from different disciplines such as phonetics, phonology, psycholinguistics, bioacoustics and sociolinguistics and the team should be selected carefully according to their expertise area and responsibilities during a possible research study. A word list can be prepared from the most common sentences to less common ones for a recognition test. Besides, a mixture of Turkish and foreign words or sentences can be used to prevent the listeners understanding through simulation. Different modes and techniques of whistling can be recorded for the same test data to examine their effect on the recognition results. A topology of whistler profiles can be investigated to see their effect on the tests. Besides, both audio and video recordings of each participant should be taken to make possible further investigation on the results such as audio-visual analysis. The test data should be recorded both at a short distance and far-distance to evaluate distance effect on the recognition. Spontaneous sentences in daily life can be recorded and used during the tests to support the compatibility of tests to natural conditions. Speakers should pronounce words and sentences in spoken form and whistled forms. The same test can be repeated with the same speakers in different day and different medium to make possible to evaluate the effect of changing conditions on the test data. Many other different techniques of whistling can be considered and should be discussed again and again before starting to a test to collect data. Therefore, a test procedure including all linguistic and acoustic test details should be prepared and approved by all participants for a possible research study on TWsL. Ethic rules should also be taken into account such as required permissions or some sensitivities of speakers during the tests.

\section{Conclusion}

In this study, the results of early research studies on TWsL have been discussed 
and their approaches to analyze a whistled speech are examined. The reason of selection of old studies on the subject is because of the fact that there are still few research studies on Turkish whistle language and most of them were performed in the past. The results of these old research studies could give valuable information for us to conduct a new research study on the subject. From the results of past studies it has been seen that although different scientists used their own methodologies for testing and evaluation of TWsL, when it comes to recognition and understandability, there seems to be common understanding that TWsL is a simplified form of Turkish Language. This paper analyzed all these studies in a comparative form and drew attention to some controversial results of them. One of the inferences from the test conditions is that there is no standard methodology to evaluate a whistle language in acoustic and phonetic aspect. In this manner, the paper opens a discussion about the definition of the test and evaluation conditions for an acoustic and/or linguistic analysis of TWsL. For this purpose, a case study is proposed to describe some possible test conditions for an acoustic and linguistic analysis of the Turkish whistle language.

The Department of Intangible Cultural Heritage in the UNESCO, which inscribes and lists the whistled languages used in the World, inscribed TWsL to this list in 2017. However, to prevent this very specific language from disappearing, it is important to take some extra precautions. For instance, instruction programs in schools should be initiated to transfer Kuskoy residents' own oral language to the next generations. Furthermore, the acoustic and linguistic properties of TWsL should be tested and examined again by a multidisciplinary team. This multidisciplinary research team should include the scientists from different disciplines such as phonetics, linguistics, acoustics and sociology. Afterwards, comprehensive tests should be implemented after preparation of detailed test documents and then audio and video recordings should be collected for further analysis of the language.

\section{Conflicts of Interest}

The authors declare no conflicts of interest regarding the publication of this paper.

\section{References}

Aksan, D. (1968). Anadoluda Islik Dili Araştirmasi On Raporu, Ankara Universitesi Dil Tarih Cografya fakultesi. Turkoloji Dergisi, 1/3, 49-64.

Baskan, O. (1968). Türkçe Islık dili. Istanbul Universitesi Türk Dili ve Edebiyati Dergisi, $16 / 1,1-10$.

Busnel, R. G. (1976). Whistled Languages. Berlin: Springer-Verlag. https://doi.org/10.1007/978-3-642-46335-8

Cowan, G. M. (1948). Mazateco Whistle Speech, Language. Language, 24, 280-286. https://doi.org/10.2307/410362

Meyer, J. (2007a). Whistled Turkish: Statistical Analysis of Vowel Distribution and Consonant Modulations. In Proceedings of XVI International Conference of Phonetic 
Sciences (pp. 284-288). Saarbrucken.

Meyer, J. (2007b). Acoustic Features and Perceptive Cues of Songs and Dialogues in Whistled Speech: Convergences with Sung Speech. In Proceedings of the International Symposium on Musical Acoustics 2007 (pp. 1-8). Barcelona.

New York Times (1964). Turkish Town Talk in Whistles. 1 March 1964. 